\title{
Regulation of focal complex composition and disassembly by the calcium-dependent protease calpain
}

\author{
Amit Bhatt ${ }^{1}$, Irina Kaverina ${ }^{2}$, Carol Otey ${ }^{3}$ and Anna Huttenlocher ${ }^{1, *}$ \\ ${ }^{1}$ Department of Pediatrics and Pharmacology, University of Wisconsin, 1300 University Avenue, University of Wisconsin Medical School, Madison, \\ WI 53706, USA \\ ${ }^{2}$ Institute of Molecular Biology, Austrian Academy of Sciences, Salzburg A-5020, Austria \\ ${ }^{3}$ Department of Cell and Molecular Physiology, University of North Carolina, Chapel Hill, NC 27599, USA \\ *Author for correspondence (e-mail: huttenlocher@facstaff.wisc.edu)
}

Accepted 12 June 2002

Journal of Cell Science 115, 3415-3425 (2002) (C) The Company of Biologists Ltd

\begin{abstract}
Summary
Cell migration requires the regulated and dynamic turnover of adhesive complexes. We have previously demonstrated that the calcium-dependent protease, calpain, regulates the organization of adhesive complexes and cell detachment during cell migration. Evidence is now provided that inhibiting calpain through over-expression of the endogenous inhibitor of calpain, calpastatin, and pharmacological inhibitors results in an inhibition of adhesive complex disassembly with stabilization of GFPvinculin and GFP/RFP-zyxin at the cell periphery. Calpain was also required for the microtubule-mediated turnover of adhesive complex sites after nocodazole wash-out, suggesting that calpain may mediate focal complex disassembly downstream of microtubules. Using dual imaging of RFP-zyxin and GFP- $\alpha$-actinin, we observed a temporal and spatial relationship between $\alpha$-actinin localization to focal contacts and the subsequent
\end{abstract}

\section{Introduction}

Cell migration is essential for normal embryonic development, wound healing, tumor invasion and metastasis as well as the inflammatory response and requires regulated cell substratum adhesion (Trinkaus, 1984). Integrin receptors are a family of heterodimeric cell surface adhesion receptors that link the extracellular matrix to the actin cytoskeleton. Integrins cluster in the membrane to form organized adhesive contact sites called focal complexes or focal adhesions (Hynes, 1992; Schoenwalder and Burridge, 1999). To migrate, cells must coordinately assemble and disassemble integrin-containing adhesive contacts, with regulated adhesion formation at the cell front and release at the cell rear (Huttenlocher et al., 1995; Lauffenburger and Horwitz, 1996). Adhesive contact sites are highly dynamic structures that undergo regulated assembly, disassembly and translocation in both stationary and migratory cells (Smilenov et al., 1999; Katz et al., 2000; Zamir et al., 1999). While progress has been made in understanding mechanisms involved in adhesion complex formation, the mechanisms that regulate adhesion complex disassembly and translocation remain largely unknown.

Our recent studies support a role for the calcium-dependent protease calpain in cell detachment (Huttenlocher et al., 1997). disassembly or translocation of RFP-zyxin containing focal complexes in areas of cell retraction. Calpain inhibition disrupted $\alpha$-actinin localization to zyxin-containing focal contacts and focal complex disassembly or translocation to the cell center. In addition, disrupting $\alpha$-actinin localization to focal complexes through expression of the $\alpha$-actinin rod domain, but not the head domain, resulted in inhibition of focal adhesion disassembly similar to calpain inhibition. Our studies suggest a novel mechanism of action whereby calpain may modulate $\alpha$-actinin localization into focal complexes and their subsequent disassembly or translocation.

Movies available on-line

Key words: Migration, Calpain, Cytoskeleton, Focal adhesion, $\alpha$ actinin
Calpain is a cysteine protease with two characterized isoforms, $\mu$ - and m-calpain (Croall and De Martino, 1991). Both contain an $80 \mathrm{kDa}$ catalytic subunit and a $30 \mathrm{kDa}$ regulatory subunit. Calpain has many substrates in vitro including the focal adhesion proteins integrin (Du et al., 1995), FAK (Cooray et al., 1996), ezrin (Potter et al., 1998) and talin (Beckerle et al., 1987). The relevance of these calpain substrates to calpain function in vivo has yet to be determined. However, the critical importance of this protease to normal embryonic development has recently been demonstrated by studies in which targeted disruption of the $30 \mathrm{kDa}$ calpain subunit, CAPN4, is embryonic lethal at day 10-11 and causes defects in vascular development (Arthur et al., 2000). We previously reported that cell permeable calpain inhibitors reduce cell migration rates and cell detachment during migration (Huttenlocher et al., 1997; Palecek et al., 1998). Further, we showed that calpain inhibition stabilizes peripheral adhesive complexes that contain vinculin and integrin. Interestingly, disruption of other proteins implicated in regulating cell migration, including FAK (Ilic et al., 1995; Sieg et al., 1999) and Src (Klinghoffer et al., 1999), also promote the formation of strong focal adhesions at the cell periphery. Together, these findings suggest that calpain and calpain substrates, such as FAK and Src, may be acting by related mechanisms to regulate cell migration. 


\section{Journal of Cell Science 115 (17)}

Recent evidence supports a central role for microtubules in the specific targeting of adhesive complex sites and their disassembly during cell migration (Kaverina et al., 1998). Kaverina et al. proposed a model whereby microtubules specifically target and deliver 'relaxing' signals to focal contact sites to promote their dissociation (Kaverina et al., 1999; Kaverina et al., 2000). However, the mechanisms through which microtubules mediate the disassembly of adhesions have not been defined. Signaling molecules that are probably involved include the Rho family of GTPases, since microtubule disruption leads to Rho activation and the formation of focal adhesions and stress fibers (Danowski et al., 1989; Bershadsky et al., 1996; Enomoto, 1996). Recent evidence supports a role for the microtubule-dependent regulation of contractility with localized inhibition of contractility as a mechanism to promote adhesion complex disassembly (Kaverina et al., 1999).

In this study we sought to determine whether calpain modulates the dynamics and composition of adhesive contacts. We found that inhibiting calpain through overexpression of the endogenous inhibitor of calpain, calpastatin and pharmacological inhibitors results in an inhibition of adhesive complex disassembly with a stabilization of GFP-vinculin and GFP-zyxin at the cell periphery, which implicates calpain as a regulator of adhesive complex dynamics in adherent cells. We also found that calpain inhibition disrupts $\alpha$-actinin localization to focal contacts and that localization of $\alpha$-actinin is important for the subsequent disassembly or translocation of zyxin-containing contact sites.

\section{Materials and Methods}

\section{Vectors}

EGFP- $\alpha$-actinin was made as previously described (Edlund et al., 2001). The calpastatin cDNA was provided by M. Maki (Nagoya University, Japan) (Maki et al., 1989; Murachi et al., 1980) and was sub-cloned into pcDNA 3.1 using the EcoRI sites. GFP-vinculin construct was provided by A. Bershadsky and B. Geiger (The Weizmann Institute of Science, Israel). EGFP-tubulin and EGFPzyxin were provided by J. Wehland (GBF, Braunschweig). RFP-zyxin was constructed by subcloning EGFP-zyxin into N1red (Clonetech) using BamHI and HindIII. GFP-calpastatin was constructed by PCR using calpastatin cDNA and forward primer: gcaaatgcggecgcatgcatcccacagaaacc and reverse primer: gcttgtgaattctgagtcatctttggcttgga. PCR product was then cloned into vitality hrEGFP (Stratagene) using restriction sites NotI and EcoRI and sequenced. The $\alpha$-actininhead-domain-GFP fusion protein was constructed by limited digest of $\alpha$-actinin-GFP (Edlund et al., 2001) with AflIII such that the Cterminal $1.913 \mathrm{~kb}$ remained fused to GFP. $\alpha$-actinin rod domain was generated by PCR using forward primer cccaagcttcatcatggactctggagcccagaaggcggag and reverse primer cccaagcttgaggtcactctc. PCR product was then cloned into pEGFP-N1 vector (Clontech) using HindIII.

\section{Antibodies and reagents}

Fibronectin was purified from human plasma by affinity chromatography as described (Ruoslahti et al., 1982). Fibronectin for the CAR fibroblast experiments was purchased from Boehringer Mannheim. Anti-vinculin antibody was purchased from Sigma (St Louis, MO) and used at a 1:500 dilution. Rhodamine-phalloidin was obtained from Molecular Probes (Eugene, OR) and used at a dilution of 1:1000. Anti-tubulin antibody was obtained from J. Wehland (GBF, Braunschweig). Nocodozole was purchased from Sigma and was used at a concentration of $2.4 \mu \mathrm{g} / \mathrm{ml}$. Calpain inhibitor, N-acetyl-leucinyl- leucinyl-norleucinal (ALLN), was obtained from Calbiochem (San Diego, CA) and used at a concentration of $50 \mu \mathrm{g} / \mathrm{ml}$ and stored as a $10 \mathrm{mg} / \mathrm{ml}$ stock in ethanol at $-20^{\circ} \mathrm{C}$. PD150606 was used at a concentration of $1 \mu \mathrm{M}$ and stored as a stock of $100 \mathrm{mM}$ in DMSO at $-20^{\circ} \mathrm{C}$.

\section{Cells and transfections}

Goldfish fin fibroblasts (CAR) were obtained from American Type Culture Collection (ATCC) and maintained in basal Eagle medium supplemented with Hanks BSS, non-essential amino acids, and $15 \%$ fetal calf serum at $25^{\circ} \mathrm{C}$. (Sigma) Chinese hamster ovary (CHOK1) cells were obtained from ATCC and maintained in Dulbecco's modified Eagles medium (Cellgro $\AA$, Mediatech, Herden, VA) supplemented with non-essential amino acids, $10 \%$ fetal bovine serum, $100 \mathrm{U} / \mathrm{ml}$ penicillin, and $100 \mu \mathrm{g} / \mathrm{ml}$ streptomycin (Sigma) at $37^{\circ} \mathrm{C}$ with $10 \% \mathrm{CO}_{2}$. CAR fibroblasts were transfected as described (Kaverina et al., 1999). Briefly, a monolayer of cells was cotransfected with $1 \mu \mathrm{g}$ EGFP-zyxin and $2 \mu \mathrm{g}$ EGF-tubulin using $15 \mu \mathrm{l}$ of superfect reagent as described (Qiagen, Valencia CA) (Kaverina et al., 1999). Cells were used 24 hours after transfection. CHO cells were transfected with $4 \mu \mathrm{g}$ of DNA and $14 \mu \mathrm{l}$ of lipofectamine as described by the manufacturer (Gibco BRL Life Technologies, Grand Island, NY). Cells were used between 36 and 48 hours after the start of the transfection. For co-transfections, the GFP-tagged cDNA was transfected at a 1:6 ratio with either control vector or calpastatin cDNA. We found that over $95 \%$ of the cells that expressed the GFP construct also expressed calpastatin by direct staining for calpastatin in transfected cells. A similar protocol was used for dual imaging experiments.

\section{Time-lapse videomicroscopy}

For live fluorescent imaging, $\mathrm{CHO}$ cells were plated in CCM1 on a coverslip mounted on a $35-\mathrm{mm}$ plate. The coverslip was coated with $5 \mu \mathrm{g} / \mathrm{ml}$ fibronectin for 1 hour and blocked with 2\% BSA for 30 minutes. Prior to videotaping, media was replaced with HAMS media supplemented with $4 \mathrm{mM}$ L-glutamine, $1 \mathrm{mM}$ non-essential amino acids, $10 \%$ fetal bovine serum, $100 \mathrm{U} / \mathrm{ml}$ penicillin, and $100 \mu \mathrm{g} / \mathrm{ml}$ streptomycin (Sigma). Cells were placed directly on a heated stage and supplemented with $\mathrm{CO}_{2}$ to maintain a $\mathrm{pH}$ of 7.0-7.5. Fluorescent images were captured every 3 minutes for 1.5-2 hours using a heated $60 \times / 1.4 N A$ objective on a Nikon inverted microscope attached to an ORCA II cooled CCD camera (Hamamatsu, Japan). The objective was heated to $35^{\circ} \mathrm{C}$ by a Bioptechs objective controller (Bioptechs, Butler, PA). An electronic shutter (Ludl, Hawthorn, NY) controlled the illumination from a 100 watt mercury bulb. Cooled CCD control and image processing was done using ISEE imaging software on an SGI computer from Inovision Corporation (Raleigh, NC). The experimental results show representative cells from a minimum of five different experiments. For all studies, similar results were found using co-transfection with calpastatin, GFP-calpastatin or treating cells with the cell-permeable calpain inhibitor, ALLN.

\section{Immunofluorescence microscopy}

Glass coverslips were acid washed, coated with fibronectin and blocked with 2\% BSA using a previously described protocol (Huttenlocher et al., 1998) with minor modifications. Cells were allowed to adhere for 12 hours at $37^{\circ} \mathrm{C}$ and $10 \% \mathrm{CO}_{2}$ after which they were fixed and stained as described (Huttenlocher et al., 1996).

\section{Supplemental processing}

Supplemental processing of videotapes from SGI ${ }^{\circledR}$ format to QuickTime ${ }^{\circledR} 4.0$ format was done using Adobe Premier 5.0®. Captured images were processed using Adobe PhotoShop ${ }^{\circledR}$ 5.0. Focal 
adhesion turnover was quantified using previously described methods (Kaverina et al., 2000). In brief, vinculin containing focal complexes were tracked for a 30 minute interval and the number of contacts that disappeared over this interval were counted and presented as a percentage of the total initial contact sites. Co-localization was determined for each condition in at least 14 cells using Isee analytical software. Co-localization was defined as the number of red pixels above background that overlapped with the green pixels above background divided by the total number of red pixels. Background fluorescence for each channel was determined in the interior of the cell and used to eliminate noise or un-localized signal.

\section{Online supplemental material}

The online version of this article contains movies that accompany several of the figures (http://jcs.biologists.org/supplemental). Movie 1: cells co-transfected with GFP-vinculin and control vector. Movie 2: cells co-transfected with GFP-vinculin and calpastatin. Movie 3: cells co-transfected with GFP-zyxin and control vector. Movie 4: cells co-transfected with GFP-zyxin and calpastatin. Movie 5: cells cotransfected with hrEGFP and RFP-zyxin. Movie 6: cells cotransfected with hrEGFP-calpastatin and RFP-zyxin. Movie 7: cells co transfected with GFP- $\alpha$-actinin and control vector. Movie 8: cells co transfected with GFP- $\alpha$-actinin and calpastatin. Movies 9 and 10: control cells co-transfected with RFP-zyxin and GFP- $\alpha$-actinin. Movie 11: calpain inhibitor (ALLN)-treated cells co-transfected with RFP-zyxin and GFP- $\alpha$-actinin. Movie 12: RFP-zyxin in cells cotransfected with full length $\alpha$-actinin. Movie 13: RFP-zyxin in cells co-transfected with the head domain of $\alpha$-actinin. Movie 14: RFPzyxin in cells co-transfected with rod domain of $\alpha$-actinin.

\section{Results}

\section{Calpain regulates adhesive complex disassembly}

We have previously reported that treatment of $\mathrm{CHO}$ cells with calpain inhibitors reduces cell migration rate and inhibits cell detachment (Huttenlocher et al., 1997). Although calpain has been implicated in focal complex disassembly, it has not previously been determined whether calpain regulates disassembly of adhesive complex sites in live cells. To address the role of calpain in focal complex disassembly we used both cell permeable calpain inhibitors and transient expression of the endogenous calpain inhibitor, calpastatin or a GFP-calpastatin. In agreement with our previous findings we found that ectopic expression of GFP-calpastatin caused a loss of central focal adhesions and stress fibers, similar to the effects observed with the cell permeable calpain inhibitor ALLN (Fig. 1).

To determine whether calpain modulates focal complex turnover, we characterized the effects of transient expression of calpastatin or treatment of cells with cell permeable calpain inhibitors on the dynamics and turnover of vinculin- and zyxincontaining adhesions. To this end, we co-transfected vinculin or zyxin with either control vector or calpastatin at a 6:1 ratio as described in Materials and Methods. We found that the control cells formed small punctate vinculin- or zyxincontaining complexes that were most prominent at the cell periphery (Fig. 2). These complexes were highly dynamic and generally dispersed within 30 minutes after formation. In contrast, cells that expressed calpastatin or were treated with ALLN (Figs 1,8) had prominent vinculin- or zyxin-containing complexes at the cell periphery. These complexes frequently elongated along the cell periphery and were less likely to disassociate than the adhesive complexes from control cells (Fig. 2). The difference between these complexes was clearly demonstrated in enlargements of small regions of the cell periphery. In control cells, marked contact sites dispersed and new ones formed in subsequent images (Fig. 2). In contrast, in
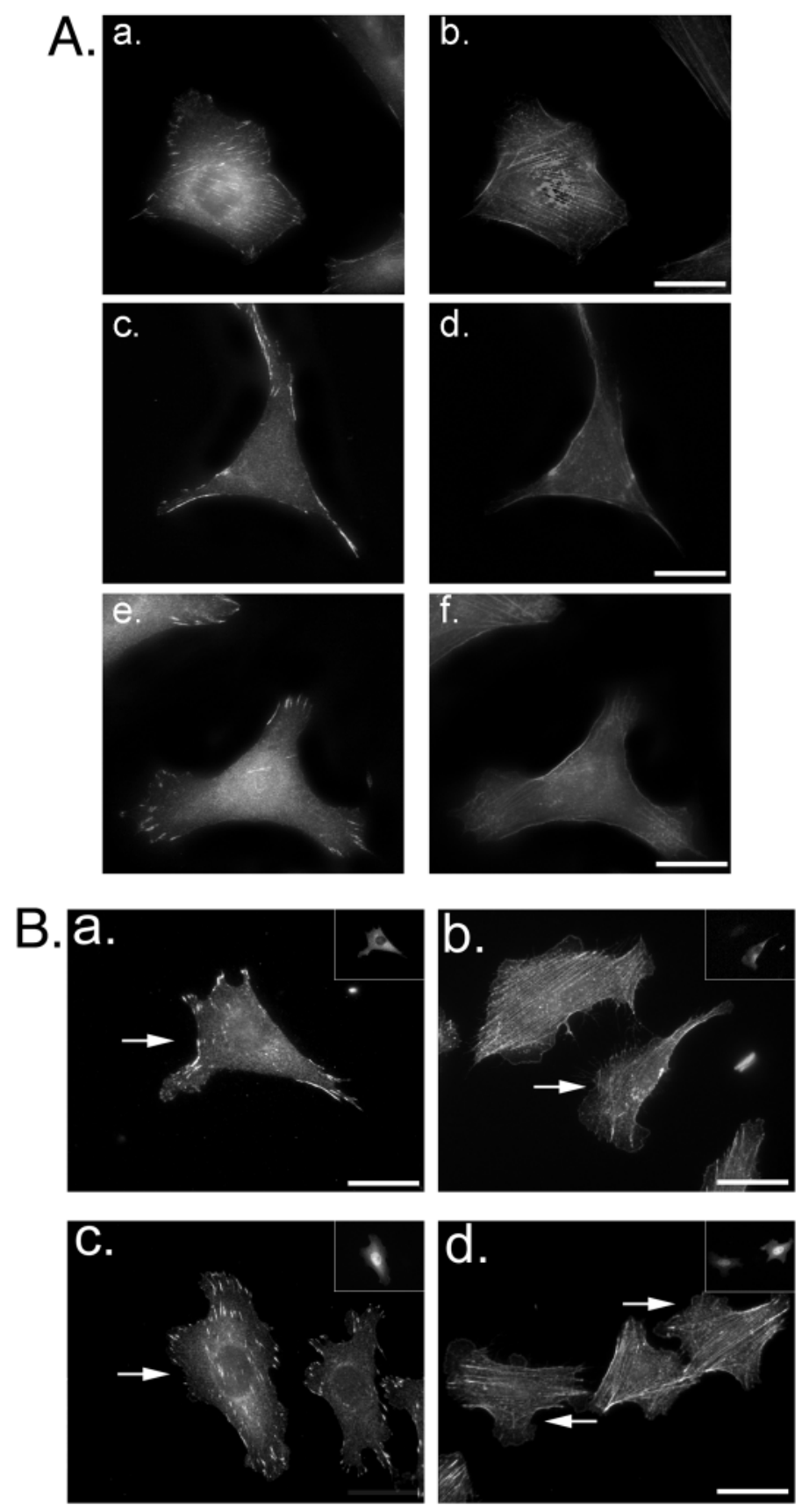

Fig. 1. Effects of calpain inhibition on the cellular morphology of $\mathrm{CHO}$ cells plated on fibronectin. (A) Cells were cultured for 12 hours on fibronectin-coated coverslips $(10 \mu \mathrm{g} / \mathrm{ml})$ and co-stained for vinculin (a,c,e) and actin (b,d,f). Cells that expressed calpastatin (c,d) or those treated with ALLN (e,f) demonstrated fewer but larger, more peripheral focal adhesions than controls $(\mathrm{a}, \mathrm{b})$. There was also a loss of central actin stress fibers after calpain inhibition. (B) Cells expressing hrEGFP-calpastatin $(a, b)$ displayed similar effects on vinculin and actin distribution to those of control cells (c,d). Insets show GFP-positive cells and arrows show corresponding cells. The cells presented are representative of the phenotype observed from a minimum of three separate experiments. Bars, $10 \mu \mathrm{m}$. 
cells that expressed calpastatin or were treated with calpain inhibitors, there were fewer contact sites and these sites were more stable in the time frame of observation. To quantify this effect, we analyzed ECM-contact fate in seven cells that express EGFP-vinculin, in several experiments using a variation of previously described methods (Kaverina et al., 1999). In control cells, $66 \%$ of 113 contact sites disappeared after 30 minutes. In contrast, $27 \%$ of 57 contact sites dispersed in the cells that express calpastatin. In general, the contact sites in the calpastatin cells remained attached to the substratum and did not translocate towards the cell center. However, we observed a few contact sites at the cell's rear that were able to detach from the substratum and translocate intact along the edge of the cell. Similar results were obtained in cells cotransfected with RFP-zyxin and GFP-calpastatin (Fig. 2). Together, these findings demonstrate that calpain modulates the disassembly of adhesive complex sites that contain vinculin and zyxin.

\section{Calpain is required for microtubule-mediated focal} complex disassembly after nocodazole wash-out

Previous reports have demonstrated that treatment of cells with nocodazole promotes the stabilization of peripheral adhesive complexes that contain focal adhesion components such as zyxin (Kaverina et al., 1999). These studies have demonstrated that microtubules specifically target and promote the disassembly of adhesive contact sites. Treatment of cells with the microtubule-disrupting agent nocodazole inhibits microtubule targeting and focal complex disassembly. After nocodazole wash-out, microtubule targeting of focal complexes occurs and promotes focal complex turnover and cell spreading. To determine whether calpain is required for the microtubule-mediated turnover of adhesive complexes, we treated cells with the calpain inhibitor ALLN and assayed focal complex fate in goldfish fin fibroblasts (CAR cells). CAR cells were used for these studies since these cells were previously used to study the effects of microtubule targeting on focal contact fate (Kaverina et al., 1999). We found that recovery of focal complex turnover after nocodazole wash-out did not occur normally in the presence of ALLN, suggesting that calpain is required for microtubule-mediated focal complex disassembly after nocodazole wash-out. Fig. 3 shows examples of contact dynamics in spread cells after recovery from nocodazole in the presence (Fig. 3b) and absence (Fig. 3a) of ALLN. After recovery from nocodazole, control cells showed increased cell spreading and turnover of adhesive complexes that contained EGFP-zyxin (53\% of contact sites disassembled; Fig. 3B). In contrast, in the presence of ALLN, the turnover of adhesive contact sites was inhibited $(21 \%$ of contact sites disassembled). These findings suggest that

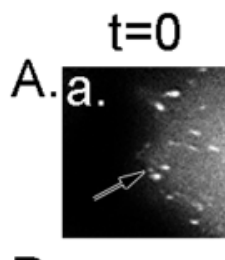

B.

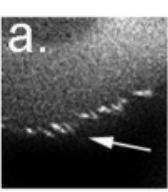

C.

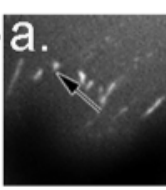

D.

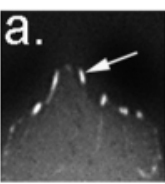

E.

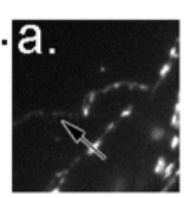

$F$

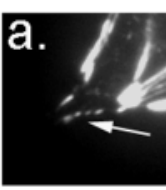

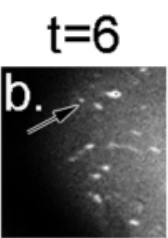
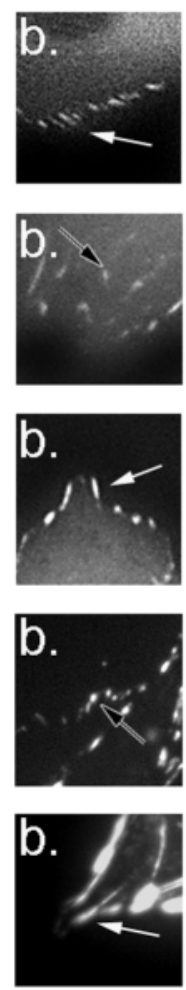
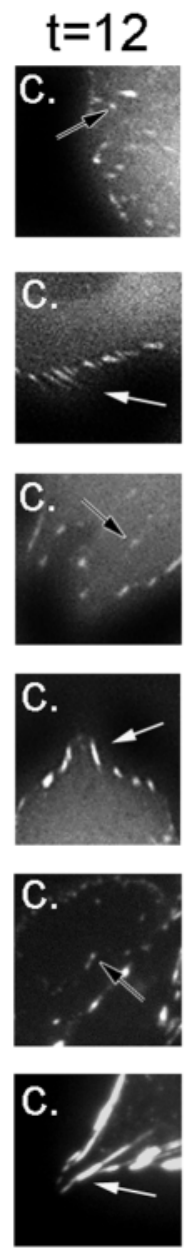
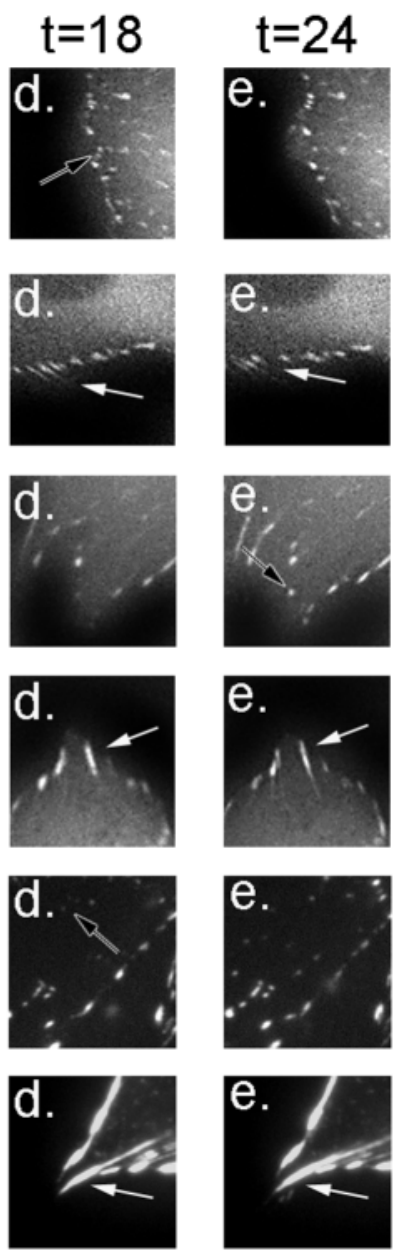

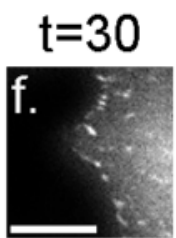

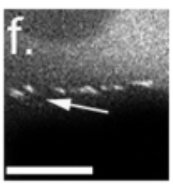
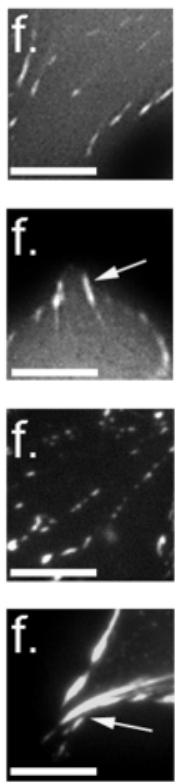

Fig. 2. Effects of calpain inhibition on the dynamics of GFP-vinculin $(\mathrm{A}, \mathrm{B})$ and GFP/RFP-zyxin $(\mathrm{C}-\mathrm{F})$ in $\mathrm{CHOK} 1$ cells plated on fibronectin $(10 \mu \mathrm{g} / \mathrm{ml})$. Video sequence of magnified regions of cells cotransfected with GFP-vinculin and control vector (A) or calpastatin (B), co-transfected with GFP-zyxin and control vector $(\mathrm{C})$ or calpastatin (D), or co-transfected with RFPzyxin and hrEGFP (E) or hrEGFPcalpastatin $(\mathrm{F})$. Frames are from 6 minute intervals $(\mathrm{t}=0,6,12,18,24$ and 30 minutes). GFP-vinculin and GFP- or RFP-zyxin-containing adhesions in cells that expressed calpastatin (B and D/F,

respectively) are larger, more peripheral and stabilized. White arrows show position of adhesive contact sites that were stabilized. In comparison, control cells have smaller more dynamic GFPvinculin and GFP-zyxin-containing adhesions. Open arrows show the position of representative contacts sites that turnover. Representative images from a minimum of five separate experiments with more than 10 cells viewed per condition (Movies 1-6). Bars, $10 \mu \mathrm{m}$. 
calpain is required for microtubule-mediated disassembly of adhesive complex sites after nocodazole wash-out.

To determine whether calpain modulates focal complex disassembly by affecting microtubule function, we studied the effects of the calpain inhibitor ALLN, on microtubule targeting after recovery from nocodazole in the presence and absence of ALLN. Control cells showed targeting of peripheral adhesive complexes stained for paxillin 10 minutes after nocodazole wash-out and focal complex disassembly 1.5 hours after washout (Fig. 4). In contrast, in the presence of ALLN, targeting of adhesive complexes occurred normally but 1.5 hours after nocodazole recovery the prominent peripheral paxillincontaining adhesive complexes remained intact despite normal microtubule targeting. These results demonstrate that calpain does not affect microtubule organization or targeting but is required for microtubule-mediated substrate contact site disassociation after nocodazole wash-out.

\section{Calpain modulates $\alpha$-actinin localization and dynamics in live cells}

To examine how calpain modulates the organization and disassembly of adhesive contact sites we examined the effects of calpain inhibition on the localization of different focal
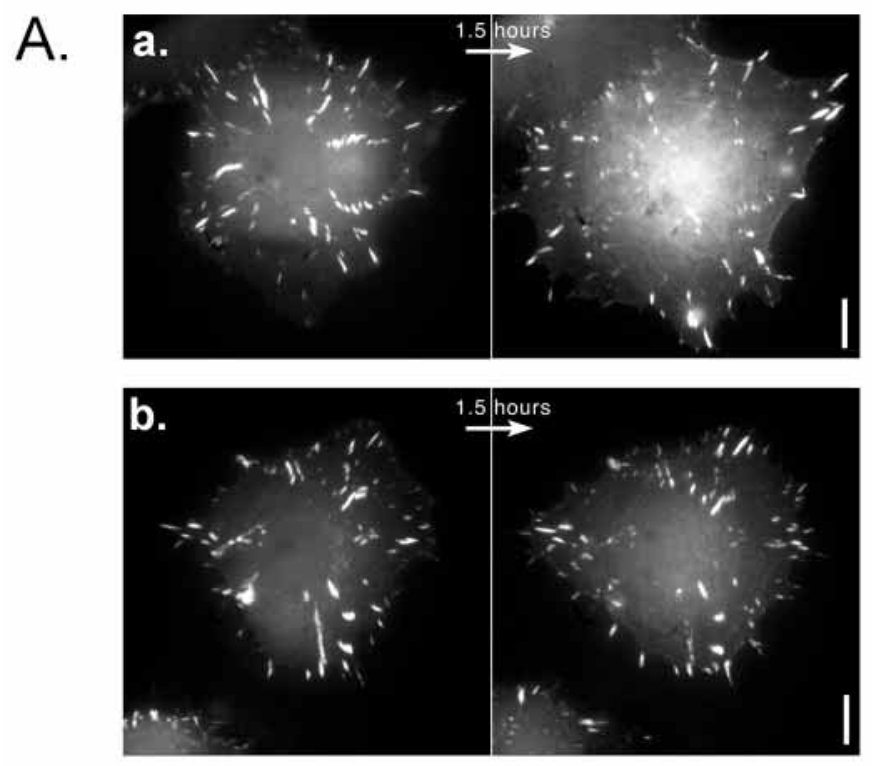

adhesion components. In contrast to the other components studied (zyxin, FAK, paxillin, integrin, talin and vinculin), the actin-binding protein $\alpha$-actinin showed reduced localization to adhesive contact sites after calpain inhibition in CHOK1 cells (Fig. 5). $\alpha$-Actinin is an actin-binding protein that crosslinks actin filaments and integrin-containing adhesive complexes, and localizes both along actin stress fibers and in focal adhesions (Otey et al., 1993). Using both antibody staining for $\alpha$-actinin and expression of an EGFP- $\alpha$-actinin fusion protein, we found that $\alpha$-actinin showed reduced localization to adhesive complex sites after calpain inhibition with ALLN or calpastatin (Fig. 5). After calpain inhibition, we found localization of $\alpha$-actinin along the cell periphery. In live imaging studies using CHOK1 cells co-transfected with the EGFP- $\alpha$-actinin and control vector or calpastatin, calpain inhibition inhibited the dynamics and localization of $\alpha$-actinin in adhesive complex sites (Fig. 5). In control cells, EGFP- $\alpha$ actinin was highly dynamic and localized in adhesive complex sites at the cell center and periphery. In contrast, expression of calpastatin induced a peripheral distribution of $\alpha$-actinin and inhibited $\alpha$-actinin dynamics. Interestingly and in contrast to $\alpha$-actinin, zyxin, which normally localizes to both focal complexes and the actin cytoskeleton, was present predominantly in focal complexes after calpain inhibition and its co-localization with $\alpha$-actinin was reduced in CHOK1 cells (Fig. 6). In control cells, $\alpha$-actinin showed $80 \%$ co-localization with zyxin but after treatment with cell permeable calpain inhibitors only $31 \%$ co-localization was observed. Immunofluorescence or co-transfection was used to characterize the zyxin-containing structures. We found that in both vehicle control and ALLN-treated cells the zyxin complexes contained $\alpha 5$-GFP-integrin (Laukaitis et al., 2001) (Fig. 7a), vinculin (Fig. 7b), paxillin, FAK and talin (data not shown). Notably, $\alpha 5$-integrin and vinculin localization to the peripheral focal complexes was more prominent in cells treated with ALLN. To determine whether nonspecific disruption of the actin cytoskeleton results in similar changes in $\alpha$-actinin and zyxin localization, cells were treated with the actindisrupting drug cytochalasin D. We found that, in contrast to calpain inhibition, cytochalasin D disrupted focal complex formation with a loss of focal adhesions at both the cell center and periphery, and did not result in a specific disruption of $\alpha$ actinin and zyxin co-localization (data not shown). Together, these findings suggest that calpain regulates the composition of focal adhesions and the specific localization of $\alpha$-actinin into adhesive complex sites.
B. Influence of ALLN on adhesion site dynamics during 1.5 hour nocodazole recovery in spreading fibroblasts (summary of results of 4 independ ent experiments)

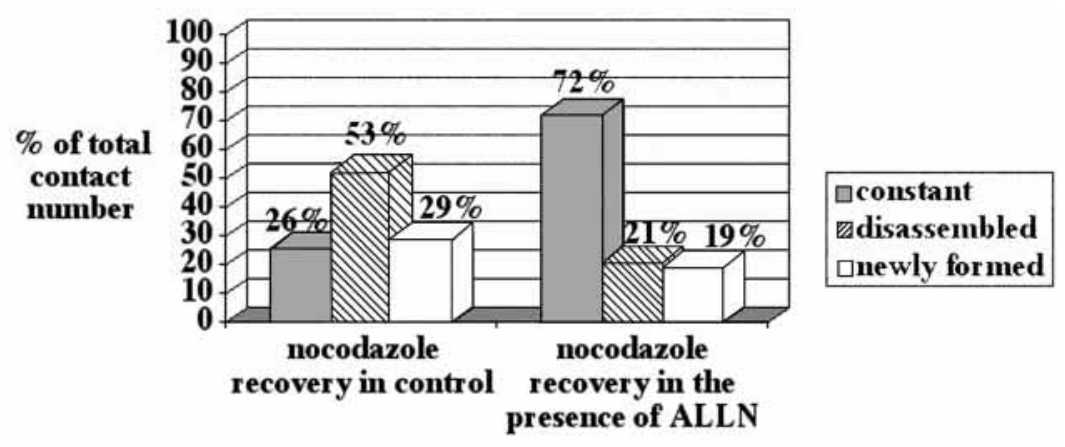

Fig. 3. Effects of calpain inhibition on focal adhesion disassociation during nocodozole recovery in cells plated on fibronectin. (A) CAR fibroblasts were transfected with EGFP-zyxin. Cells were pretreated with nocodozole (a) or nocodozole and ALLN (b) and plated in the presence of the same agents on $50 \mu \mathrm{g} / \mathrm{ml}$ fibronectin for 2 hours. Nocodozole was then washed out. Cells were allowed to recover in the presence (b) or absence (a) of ALLN. In control cells contacts were disassembled as cells spread. In cells treated with ALLN, turnover of adhesive contact sites was inhibited. Bars, $10 \mu \mathrm{m}$. (B) Quantification of contact site disassembly or formation in control and ALLN-treated cells from four separate experiments. 


\section{Effects of calpain inhibition on $\alpha$-actinin and zyxin dynamics in live cells}

To characterize the mechanism by which calpain regulates focal adhesion disassembly we examined the dynamics of zyxin and $\alpha$-actinin in live cells using dual imaging studies of cells co-transfected with RFP-zyxin and GFP- $\alpha$-actinin. This is the first study to describe the temporal and spatial distribution of zyxin and $\alpha$-actinin in live cells. As described above, control cells showed greater than $80 \%$ co-localization of zyxin and $\alpha$-actinin. We found that localization of $\alpha$-actinin into zyxin-containing focal complexes in control cells may be associated with different contact fates including stabilization of the complex, disassembly and translocation (Fig. 8). Interestingly, at areas of cell retraction, common fates included contact site disassembly and translocation to the cell center. In fact, a temporal and spatial relationship between $\alpha$-actinin localization into zyxin contact sites and their translocation was observed in areas of cell retraction. In contrast, in areas of protrusion, zyxin and $\alpha$ actinin were less associated and we did not commonly observe contact site translocation or disassembly (Movies 9-11; http://jcs.biologists.org/supplemental). These findings suggest that zyxin- $\alpha$-actinin association may promote contact site translocation and disassembly, thereby facilitating cell retraction. In the presence of cell permeable calpain inhibitors ALLN (Figs $6,8)$ and PD150606 (data not shown), colocalization of $\alpha$-actinin and zyxin was reduced. In live imaging studies, ALLN inhibited the co-localization of zyxin and $\alpha$ actinin and, under these conditions, we did not observe contact site translocation or disassembly. Together these findings suggest that $\alpha$-actinin localization to focal complexes may promote their subsequent disassembly or translocation, and that this effect may be mediated by calpain.

\section{Characterization of the role of $\alpha$-actinin during focal adhesion disassembly}

Previous studies suggest that $\alpha$-actinin localization to the focal complex is important for focal complex disassembly (Laukaitis et al., 2001; Pavalko and Burridge, 1991). Pavalko and Burridge have shown that microinjection of purified $\alpha$-actinin $53 \mathrm{kDa}$ rod domain localizes to the focal complex while the $23 \mathrm{kDa}$ head domain localizes to actin stress fibers (Pavalko and Burridge, 1991). The $\alpha$-actinin rod and head domains were thought to act as dominant negatives, competing with full-length $\alpha$-actinin for binding to the focal complex or the actin cytoskeleton, respectively. To determine whether $\alpha$-actinin localization to the focal complex is important for focal complex disassembly and translocation, GFP fusion proteins to the $23 \mathrm{kDa}$ head domain and the $53 \mathrm{kDa}$ rod domain were generated and their effects on the dynamics of RFP-zyxin were determined using live imaging. The $53 \mathrm{kDa}$ rod-domain-GFP fusion protein $(\alpha-$ actinin-rod-GFP) localized to focal adhesions while the 23 $\mathrm{kDa}$ head-domain-GFP fusion protein ( $\alpha$-actinin-head-GFP) localized predominantly to actin stress fibers, which is similar to results previously published (Pavalko and Burridge, 1991) (Fig. 9). Interestingly, disrupting $\alpha$-actinin localization to focal complexes through the expression of $\alpha$-actinin-rod-GFP
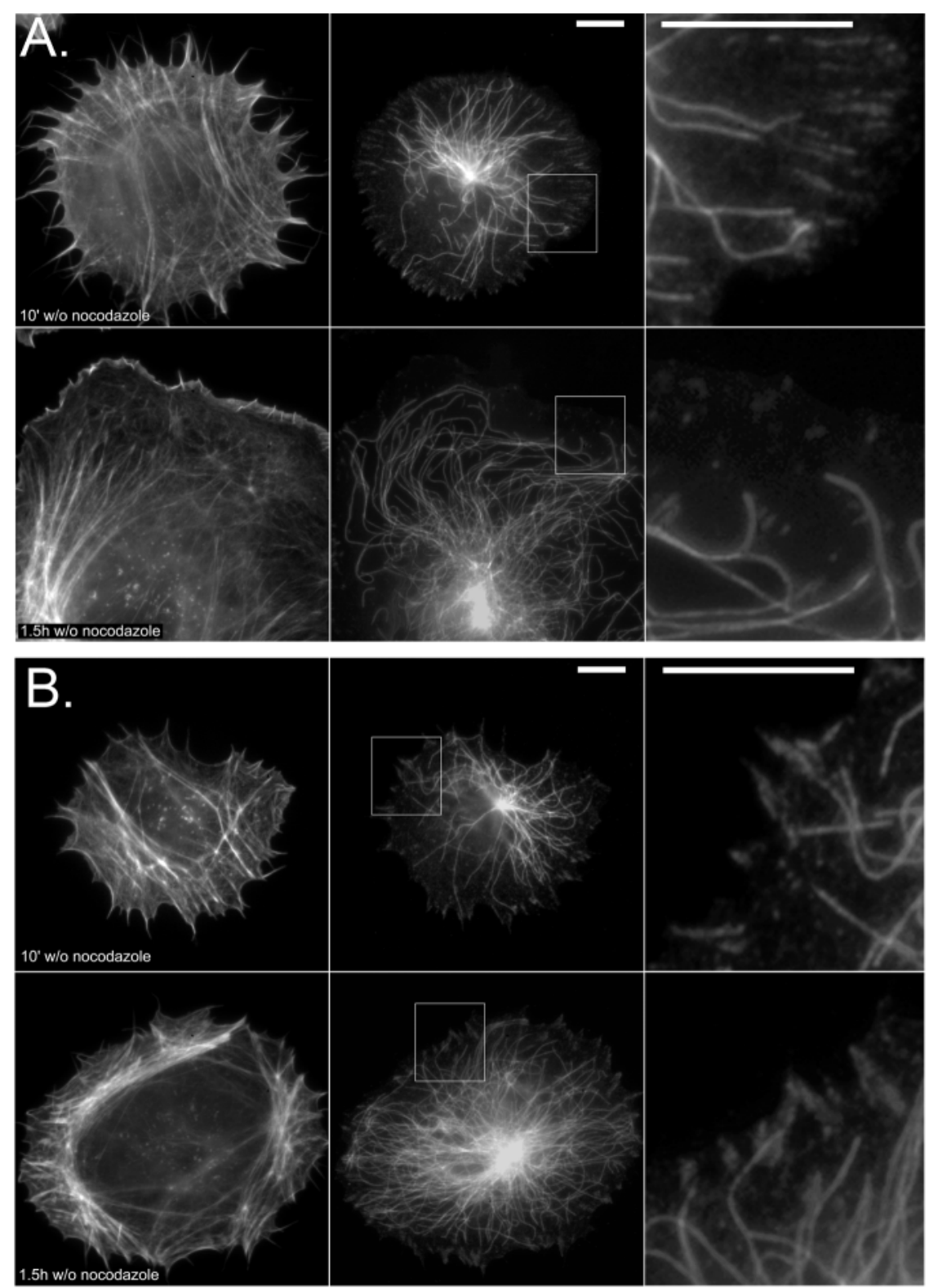

Fig. 4. Effects of calpain inhibition on focal adhesion targeting of microtubules in cells plated on fibronectin. CAR fibroblasts were stained for paxillin and tubulin. Cells were pretreated with nocodozole and plated on $50 \mu \mathrm{g} / \mathrm{ml}$ fibronectin for 2 hours before nocodozole wash-out. Cells were then allowed to recover in the presence (B) or absence (A) of ALLN and stained for actin (left panel) or paxillin and tubulin (middle and right panel). Top images were fixed 10 minutes after nocodozole wash-out and bottom images were fixed 1.5 hours after washout. Microtubule targeting occurs in the presence (B) or absence (A) of ALLN. Bars, $10 \mu \mathrm{m}$. 
inhibited focal adhesion disassembly similar to calpain inhibition. When cells were co-transfected with $\alpha$-actininrod-GFP and RFP-zyxin, fewer zyxin-containing focal complexes disassembled $(21 \%$ of focal complexes disassembled) after 30 minutes compared with expression of full-length $\alpha$-actinin-GFP (44\% of focal adhesions disassembled $P<0.003$ ) or $\alpha$-actinin-head-GFP (49\% of focal adhesions disassembled $P<0.002$ ) (Fig. 9). In addition, cells that express $\alpha$-actinin-rod-GFP did not show translocation of RFP-zyxin to the cell center, supporting a role for $\alpha$-actinin in complex site translocation (Movies 11-13). These results demonstrate that the localization of $\alpha$-actinin to focal
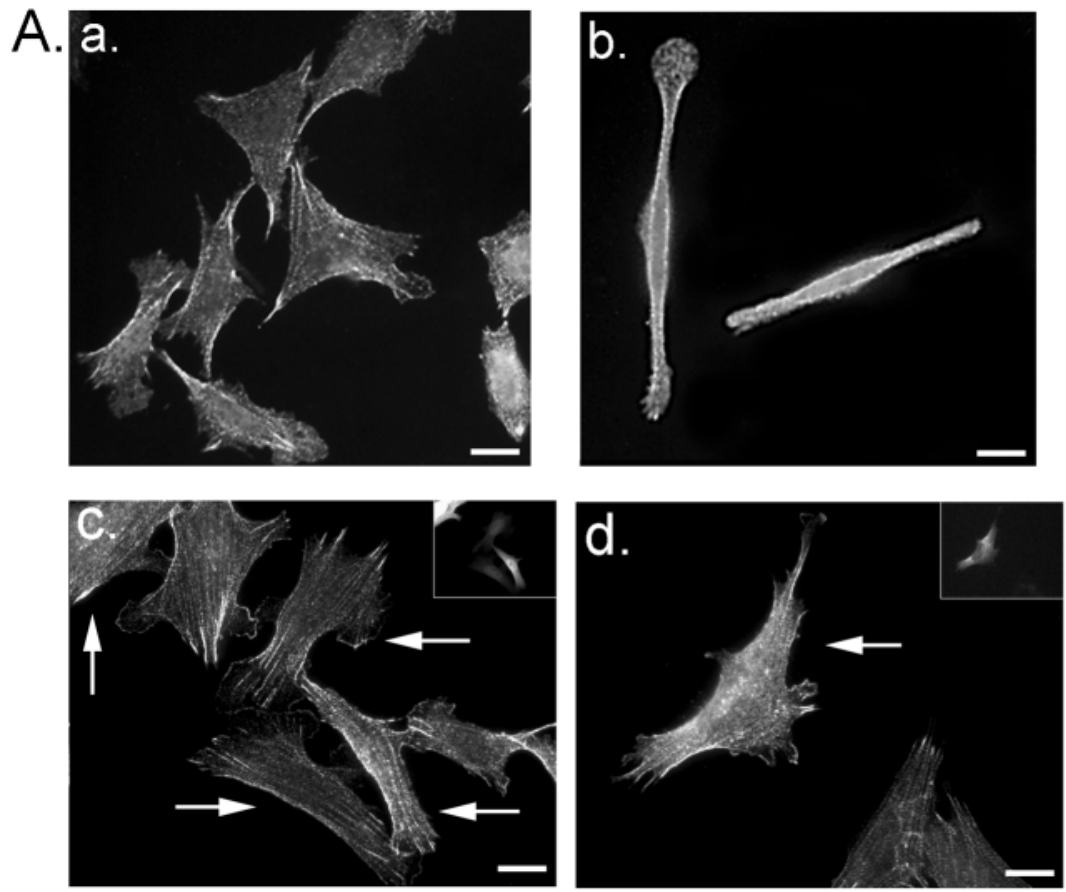

A.
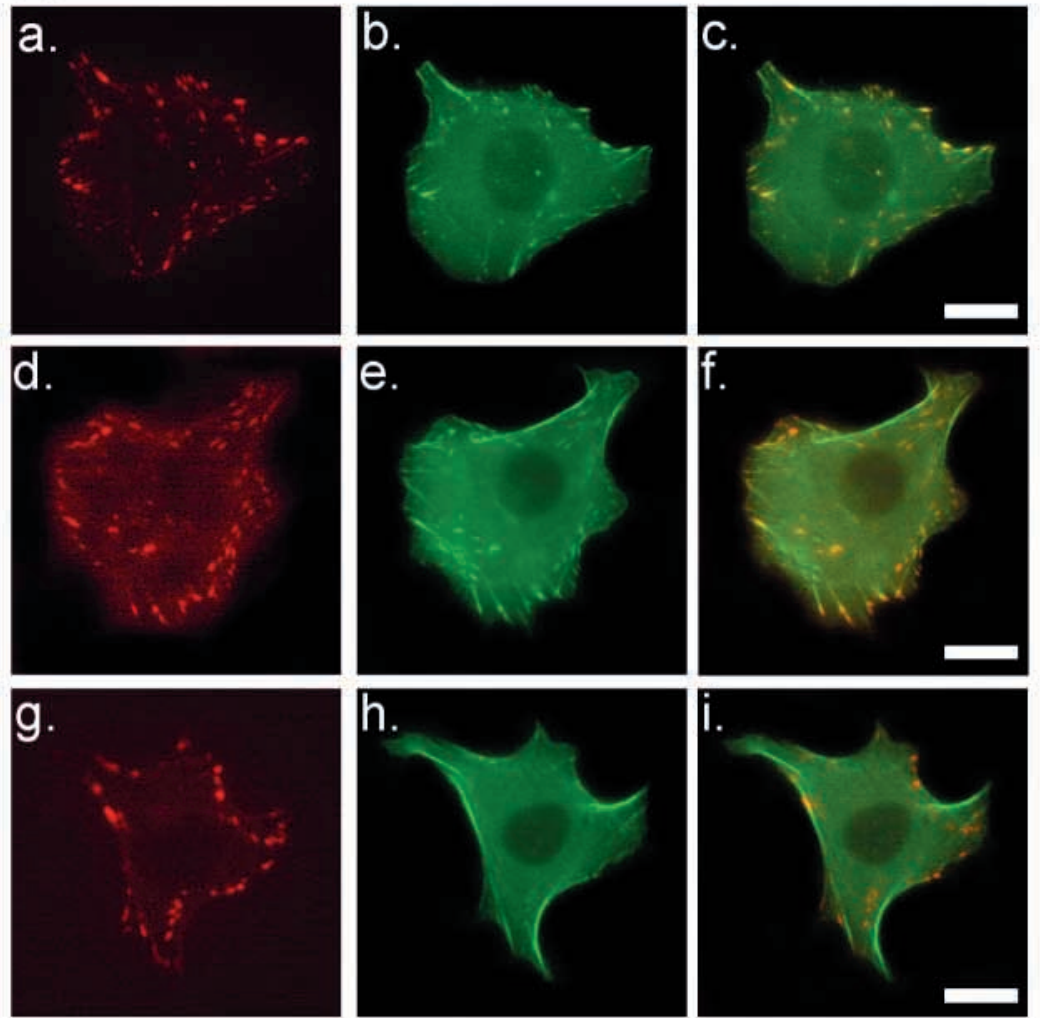
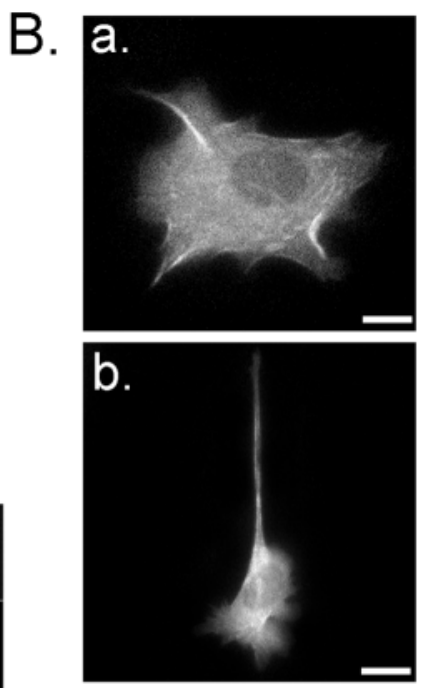

Fig. 5. Effects of

calpain inhibition on $\alpha$ actinin localization and dynamics in CHOK1 cells plated on fibronectin. (A)

Representative images of fixed cells treated with (b) and without (a) ALLN, and fixed cells that have been transfected with hrEGFP (c) or hrEGFPcalpastatin (d). Arrows and inserts show GFPpositive cells. (B) Live imaging of cells cotransfected with GFP- $\alpha$-actinin and control vector (a), and cells co-transfected with GFP- $\alpha$-actinin and calpastatin (b). GFP- $\alpha$-actinin was less dynamic and did not localize to focal complexes in cells that expressed calpastatin in comparison to control vector (Movies 7 , 8). Bars, $20 \mu \mathrm{m}$.
B.

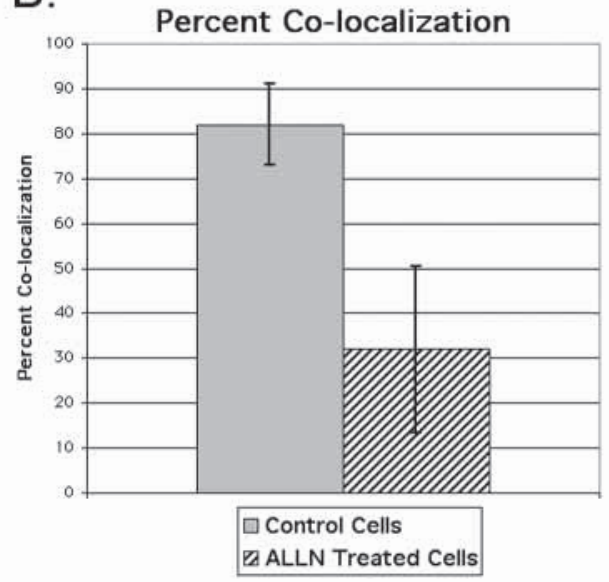

Fig. 6. Effects of calpain inhibition on RFP-zyxin and GFP- $\alpha$-actinin localization in CHOK 1 cells.

(A) Images from control cells (a-f) or cells treated with ALLN (g-i). Red shows zyxin and green shows $\alpha$ actinin; areas of co-localization appear as yellow. Zyxin showed decreased localization with $\alpha$-actininin in cells treated with ALLN. (B) Quantification of $\alpha$ actinin and zyxin co-localization in control cells or cells treated with ALLN from five separate experiments $(P<0.01)$. Bars, $10 \mu \mathrm{M}$. 
A.
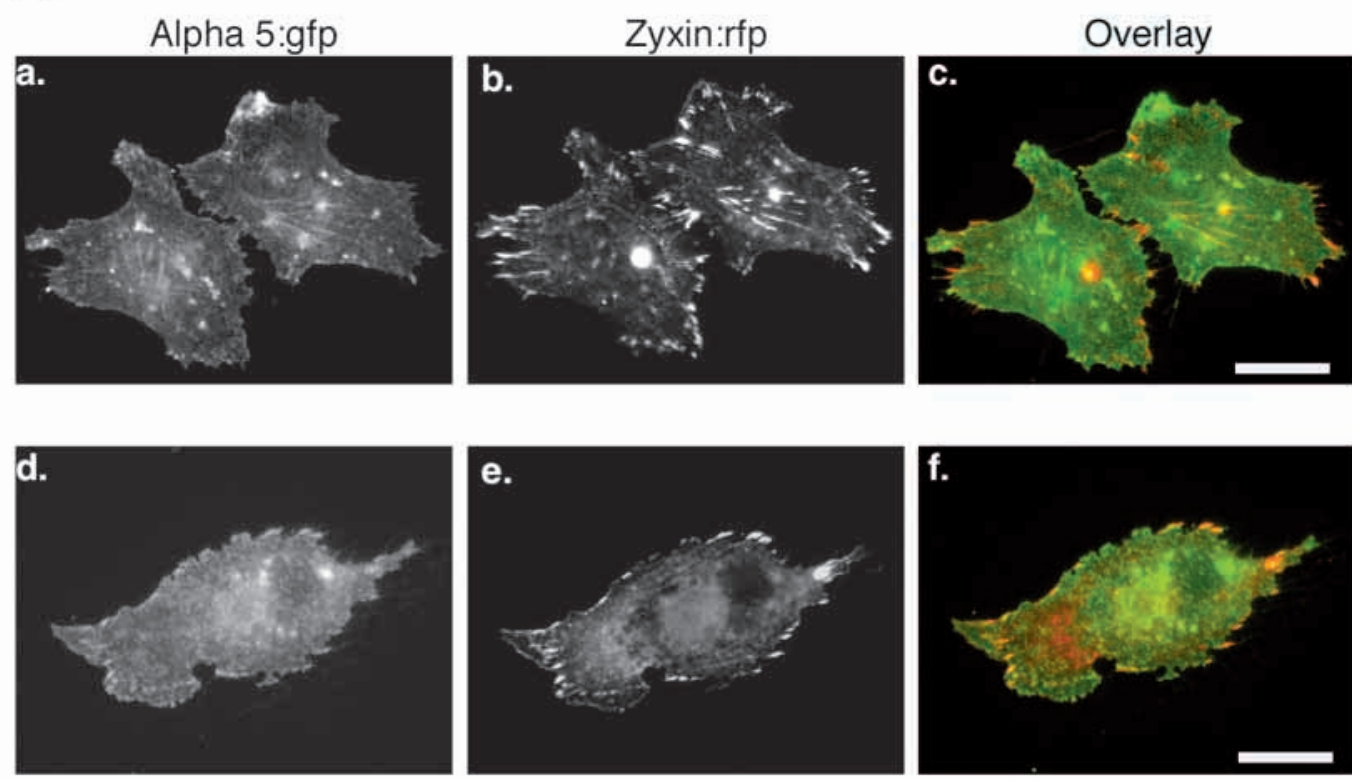

B.
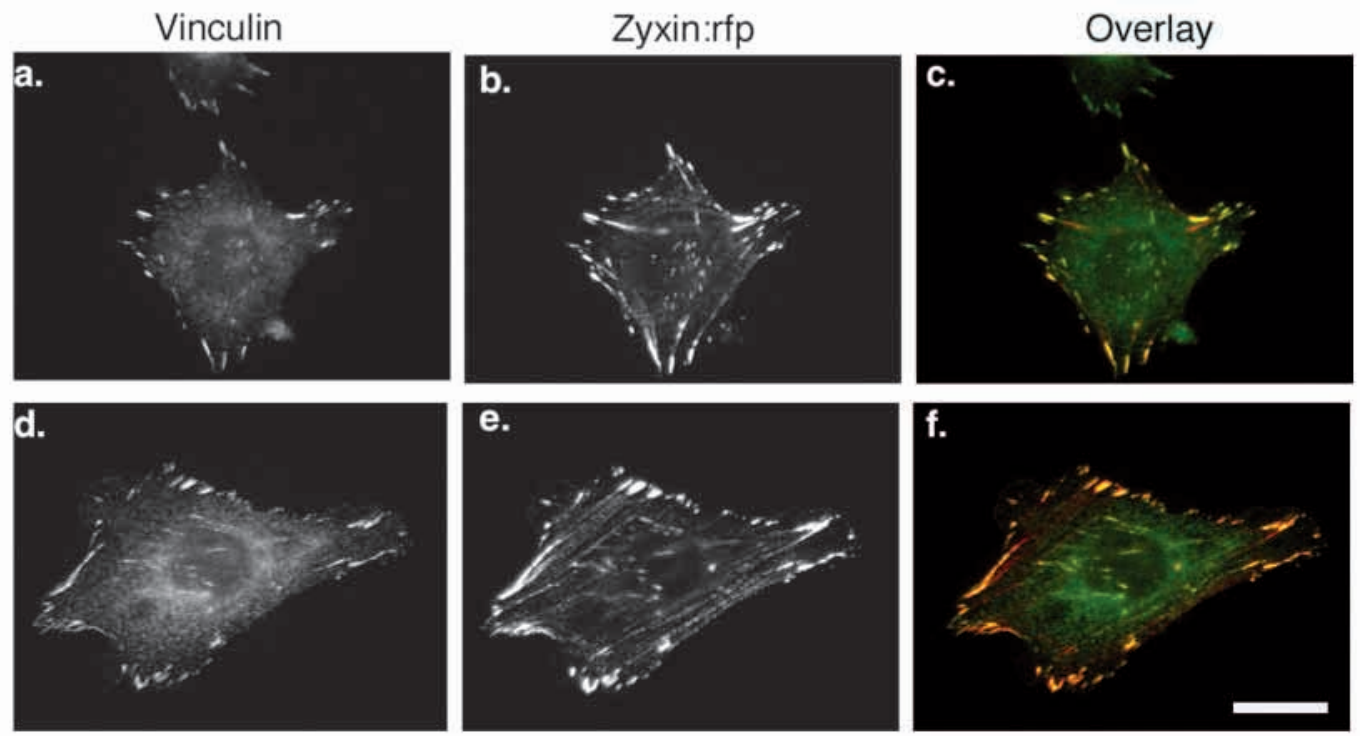

Fig. 7. Effects of calpain inhibition on the composition of zyxin-containing focal complexes. (A) CHOK1 cells co-transfected with GFP- $\alpha 5$ integrin and RFP-zyxin were treated with (d-f) or without (ac) ALLN and fixed. Zyxincontaining focal complexes contained GFP- $\alpha 5$-integrin in both control and calpaininhibited cells. (B) Cells transfected with zyxin-RFP were treated with (d-f) or without (a-c) ALLN and fixed and stained. Zyxin-containing focal complexes in both control and ALLN-treated cells contained vinculin. Bars, 20 $\mu \mathrm{m}$.

complexes is important for focal complex disassembly and translocation.

\section{Discussion}

The regulated remodeling of adhesive contact sites is critical for cell migration (Huttenlocher et al., 1995; Lauffenburger and Horwitz, 1996). In this study we found that the calciumdependent protease calpain is an important regulator of adhesive complex turnover. Using GFP-vinculin and GFPzyxin, we showed that co-expression of the endogenous inhibitor of calpain, calpastatin, or treatment of cells with cell permeable calpain inhibitors, inhibits the turnover of vinculinand zyxin-containing adhesive contact sites. Similar results were observed when cells expressed GFP-calpastatin and RFP- zyxin, directly demonstrating that cells that express ectopic calpastatin have reduced contact site disassembly. Accordingly, we also found that calpain-deficient embryonic fibroblasts that express GFP-zyxin have an inhibition of focal contact disassembly (data not shown). This is the first study to directly demonstrate that calpain mediates focal contact disassembly using live cell imaging approaches. Our studies suggest a novel mechanism of action whereby calpain may modulate $\alpha$-actinin localization into zyxin-containing focal complexes and their subsequent translocation or disassembly.

Recent studies have supported the importance of microtubules as regulators of the turnover and dynamics of focal adhesions in adherent cells. Kaverina et al. have demonstrated that the specific targeting of microtubules to substrate contact sites is required for their turnover and cell 

Treatment of cells with nocodazole, which depolymerizes microtubules, promotes the stabilization of peripheral adhesions and reduces cell protrusion and spreading. After nocodazole wash-out and recovery of the microtubular detachment in migrating cells (Kaverina et al., 1999).

network, specific targeting of peripheral adhesions promotes their turnover and allows for cell spreading, Rac activation (Waterman-Storer et al., 1999) and cell polarization (reviewed by Waterman-Storer and Salmon, 1999). The mechanism by which microtubules promote adhesive complex turnover and
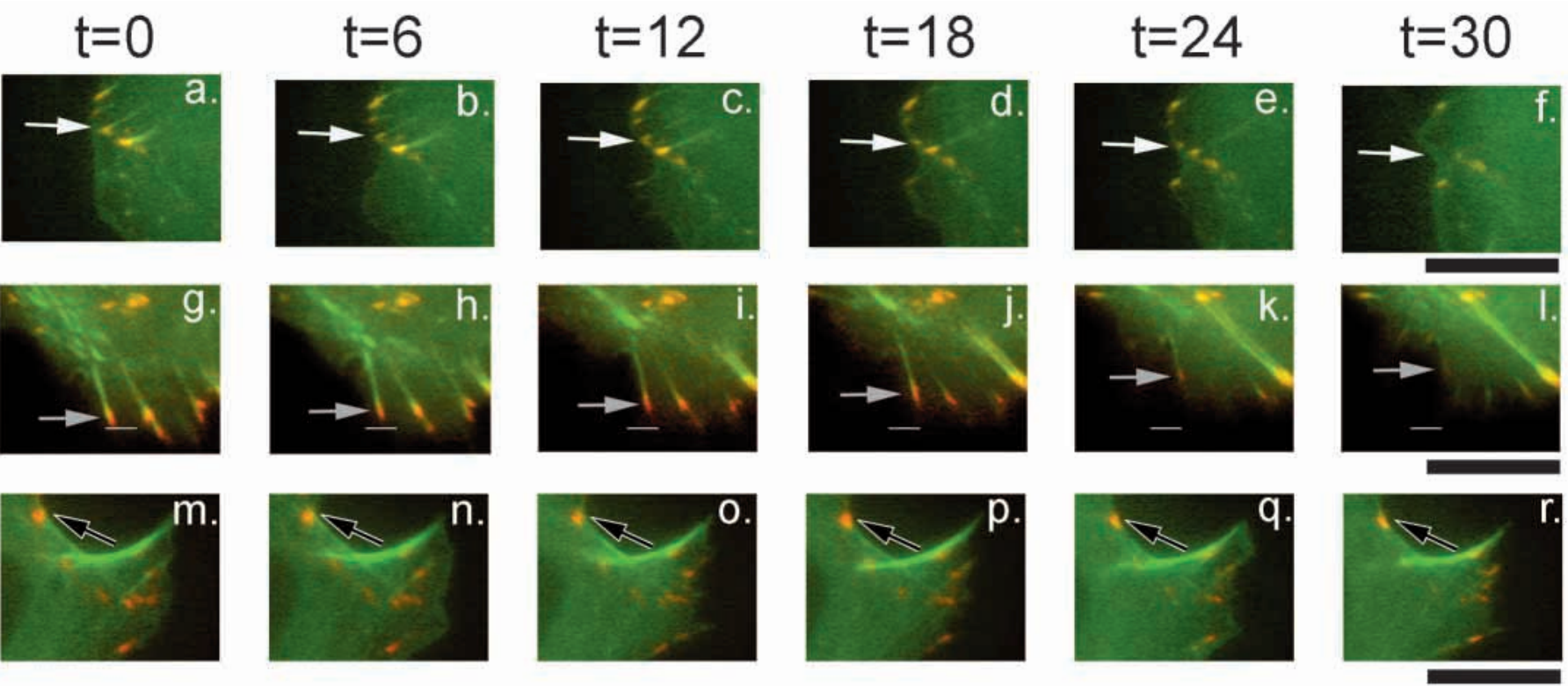

Fig. 8. Effects of calpain inhibition on RFP-zyxin and GFP- $\alpha$-actinin localization and focal complex disassembly. Video sequences of magnified regions of control cells (a-l) or cells treated with ALLN (m-r). Red shows zyxin and green shows $\alpha$-actinin; areas of co-localization appear as yellow. Images were collected at $\mathrm{t}=0,6,12,18,24$ and 30 minutes. White arrows show zyxin-containing focal complexes that disperse after $\alpha$-actinin localization. Gray arrows show zyxin-containing focal complexes that translcoate to the cell center. Open arrows show stabilized zyxin-containing focal complexes that did not co-localize with $\alpha$-actinin, and did not translocate or disperse in cells treated with ALLN (Movies 9-11). Bars, $20 \mu \mathrm{m}$.
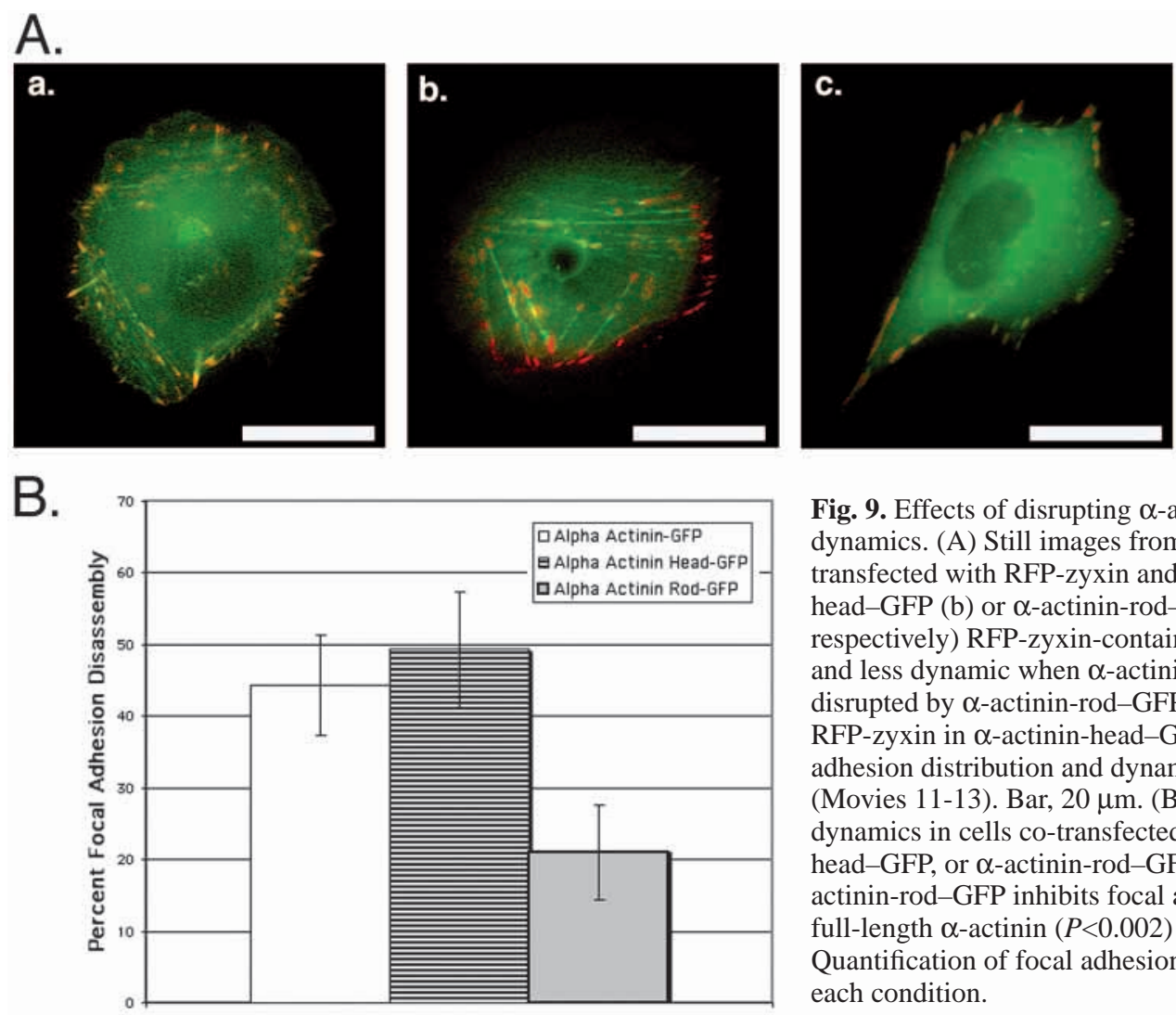

Fig. 9. Effects of disrupting $\alpha$-actinin localization on focal adhesion dynamics. (A) Still images from video sequences of CHOK1 cells cotransfected with RFP-zyxin and full-length GFP- $\alpha$-actinin (a), $\alpha$-actininhead-GFP (b) or $\alpha$-actinin-rod-GFP (c) (Movies 12, 13 and 14, respectively) RFP-zyxin-containing focal complexes are more peripheral and less dynamic when $\alpha$-actinin localization to the focal complex is disrupted by $\alpha$-actinin-rod-GFP, similar to calpain inhibition. In contrast, RFP-zyxin in $\alpha$-actinin-head-GFP co-transfected cells exhibits a focal adhesion distribution and dynamics similar to full-length GFP- $\alpha$-actinin (Movies 11-13). Bar, $20 \mu \mathrm{m}$. (B) Quantification of focal adhesion dynamics in cells co-transfected with full-length $\alpha$-actinin, $\alpha$-actininhead-GFP, or $\alpha$-actinin-rod-GFP and RFP-zyxin. Transfection of $\alpha$ actinin-rod-GFP inhibits focal adhesion disassembly when compared with full-length $\alpha$-actinin $(P<0.002)$ and with $\alpha$-actinin-head-GFP $(P<0.003)$. Quantification of focal adhesion dynamics was performed on five cells for each condition. 
cell detachment has not been elucidated, although previous studies have implicated a possible role for members of the Rho family of GTPases and/or localized regulation of contractility (Kaverina et al., 1999). We found that calpain inhibition had no effect on microtubule targeting of focal adhesion sites, but that calpain was required for microtubule-mediated turnover of focal complexes after nocodazole wash-out. Together these findings suggest that calpain may act downstream of microtubules to mediate focal complex disassembly.

In contrast to the microtubule cytoskeleton, we and others have found that calpain inhibition disrupts the actin cytoskeleton and inhibits the formation of Rho-mediated stress fibers (Kulkarni et al., 1999; Bialkowska et al., 2000). In this paper we found that calpain inhibition specifically perturbs the co-localization of zyxin and $\alpha$-actinin at focal contacts. The importance of zyxin- $\alpha$-actinin binding for cell migration has been recently demonstrated by a study showing that a peptide inhibitor that blocks zyxin- $\alpha$-actinin interactions affects zyxin localization and cell migration (Drees et al., 1999). Furthermore, earlier studies demonstrated that disruption of $\alpha$ actinin function by microinjection of $\alpha$-actinin $27 \mathrm{kDa}$ or 53 $\mathrm{kDa}$ fragments results in the disassembly of the stress fibers, but the persistence of focal adhesions at the cell periphery (Pavalko and Burridge, 1991), similar to the phenotype observed after calpain inhibition. These findings suggest that the association of $\alpha$-actinin with both actin-containing stress fibers and focal adhesions may be important for focal complex disassembly and/or translocation to the cell center. Our live imaging studies now provide direct evidence to support this possibility. We found a temporal and spatial relationship between zyxin and $\alpha$-actinin co-localization, focal contact site translocation or disassembly and the retraction of a region of the cell. These findings suggest that zyxin- $\alpha$-actinin colocalization at regions of cell retraction may mediate contact site translocation and disassembly. Zyxin- $\alpha$-actinin colocalization was disrupted after calpain inhibition. Accordingly, there was an inhibition of contact site translocation, disassembly and cell retraction. In addition, we found that disrupting $\alpha$-actinin localization to the focal complex through expression of the $\alpha$-actinin rod domain also caused an inhibition of focal complex disassembly and translocation similar to calpain inhibition. Together, these findings suggest that the ability of zyxin- $\alpha$-actinin to colocalize may be important for focal complex disassembly and translocation to the cell center, and that the zyxin- $\alpha$-actinin interaction at focal contact sites may be mediated by calpain.

The critical substrates for calpain's effects on focal complex disassembly and cell motility have remained elusive. Possibilities are broad since many focal adhesion components and related signaling proteins have been identified as calpain substrates in vitro. Likely candidates include FAK and Src, both of which are important mediators of cell migration and adhesive complex turnover. Cells deficient in FAK (Ilic et al., 1995) and Src (Klinghoffer et al., 1999) have been reported to show strong focal adhesions that occur primarily at the cell periphery, consistent with a defect in adhesive complex turnover. However, we do not find evidence for differential cleavage or phosphorylation of FAK (Dourdin et al., 2001) or Src activation (using Src kinase activity assays) in calpaindeficient embryonic fibroblasts (data not shown). Furthermore, the distribution of $\alpha$-actinin in Src and FAK-deficient cells is not comparable with the results observed after calpain inhibition or in calpain-deficient embryonic fibroblasts (data not shown), suggesting that FAK and Src are not the critical substrates for calpain's effects on focal contact disassembly. Alternatively, the focal adhesion component talin is an attractive candidate. Our recent studies demonstrate the differential cleavage of talin in control and calpain-deficient embryonic fibroblasts (Dourdin et al., 2001), which supports a critical role for talin in the regulation of the actin cytoskeleton and focal adhesions by calpain. Similarly, inhibition of calpain in CHOK 1 cells led to a $50 \%$ decrease in talin cleavage while having no detectable effect on other focal complex proteins such as $\alpha$-actinin, FAK, vinculin or paxillin (data not shown). It is possible that calpain cleaves talin and this modification of the adhesion complex permits the localization of $\alpha$-actinin into the adhesive contact site. In support of this hypothesis is the recent observation that the regulated interaction of the $\beta_{2}$ integrin with $\alpha$-actinin rather than talin requires a conformational changes that unmasks a cryptic $\alpha$-actininbinding domain in the integrin cytoplasmic domain (Sampath et al., 1998). The authors proposed a model in which a proteolysis event cleaves talin and promotes a conformational change in the integrin cytoplasmic domain that allows for $\alpha$ actinin binding to integrin. The importance of calpain in lymphocyte adhesion and spreading, suggests that the proteolysis event described by Sampath et al. (Sampath et al., 1998) may be mediated by calpain (Stewart et al., 1998).

In summary, we have shown that calpain regulates adhesive complex disassembly and that inhibiting calpain with calpastatin, stabilizes peripheral adhesive complexes and inhibits contact site disassembly and translocation. Further, we found that calpain is required for microtubule-mediated focal complex turnover but not targeting after nocodazole wash-out. Finally, our findings suggest that $\alpha$-actinin-zyxin colocalization at focal contacts may be an important component of the calpain-dependent mechanism that regulates focal complex turnover and translocation. A challenge for future studies will be to identify the critical substrate or substrates that mediate calpain's effects on focal adhesion disassembly and cell migration.

We thank V. Small, R. Horwitz, E. Cox and B. Perrin for useful discussions; A. Bershadsky and B. Geiger for the vinculin-GFP construct; M. Maki for the calpastatin cDNA; and Alison Holub for excellent technical assistance. This work was supported by the National Cancer Institute (R01 CA85862-01; 5K08 CA 76631), Austrian Science Research Council and a grant from the Shaw Foundation.

\section{References}

Arthur, J. S., Elce, J. S., Hegadorn, C., Williams, K. and Greer, P. A. (2000). Disruption of the murine calpain small subunit gene, Capn4: calpain is essential for embryonic development but not for cell growth and division. Mol. Cell Biol. 20, 4474-4481.

Beckerle, M. C., Burridge, K., DeMartino, G. N. and Croall, D. E. (1987). Colocalization of calcium-dependent protease II and one of its substrates at sites of cell adhesion. Cell 51, 569-577.

Bershadsky, A., Chausovsky, A., Becker, E., Lyubimova, A. and Geiger, B. (1996). Involvement of microtubules in the control of adhesion-dependent signal transduction. Curr. Biol. 6, 1279-1289.

Bialkowska, K., Kulkarni, S., Du, X., Goll, D. E., Saido, T. C. and Fox, J. E. (2000). Evidence that beta3 integrin-induced rac activation involves the calpain-dependent formation of integrin clusters that are distinct from the 
focal complexes and focal adhesions that form as rac and RhoA become active. J. Cell Biol. 151, 685-696.

Cooray, P., Yuan, Y., Schoenwaelder, S. M., Mitchell, C. A., Salem, H. H. and Jackson, S. P. (1996). Focal adhesion kinase (pp125FAK) cleavage and regulation by calpain. Biochem. J. 318, 41-47.

Croall, D. E. and DeMartino, G. N. (1991). Calcium-activated neutral protease (calpain) system: structure, function, and regulation. Physiol. Rev. 71, 813-847.

Danowski, B. A. (1989). Fibroblast contractility and actin organization are stimulated by microtubule inhibitors. J. Cell Sci. 93, 255-266.

Dourdin, N., Bhatt, A. K., Dutt, P., Greer, P. A., Arthur, J. S. C., Elce, J. and Huttenlocher, A. (2001). Reduced cell migration and disruption of the actin cytoskeleton in calpain-difecient embryonic fibroblasts. J. Biol. Chem. 276, 48382-48388.

Drees, B. E., Andrews, K. M. and Beckerle, M. C. (1999). Molecular dissection of zyxin function reveals its involvement in cell motility. J. Cell Biol. 147, 1549-1560.

Du, X., Saido, T. C., Tsubuki, S., Indig, F. E., Williams, M. J. and Ginsberg, M. H. (1995). Calpain cleavage of the cytoplasmic domain of the integrin beta 3 subunit. J. Biol. Chem. 270, 26146-26151.

Edlund, M., Lotano, M. A. and Otey, C. A. (2001). Dynamics of alpha-actinin in focal adhesions and stress fibers visualized with alpha-actinin-green fluorescent protein. Cell Motil. Cytoskeleton 48, 190200.

Enomoto, T. (1996). Microtubule disruption induces the formation of actin stress fibers and focal adhesions in cultured cells: possible involvement of the rho signal cascade. Cell Struct. Funct. 21, 317-326.

Huttenlocher, A., Sandborg, R. R. and Horwitz, A. F. (1995). Adhesion in cell migration. Curr. Opin. Cell Biol. 7, 697-706.

Huttenlocher, A., Ginsberg, M. H. and Horwitz, A. F. (1996). Modulation of cell migration by integrin-mediated cytoskeletal linkages and ligandbinding affinity. J. Cell Biol. 134, 1551-1562.

Huttenlocher, A., Palecek, S. P., Lu, Q., Zhang, W., Mellgren, R. L., Lauffenburger, D. A., Ginsberg, M. H. and Horwitz, A. F. (1997). Regulation of cell migration by the calcium-dependent protease calpain. $J$. Biol. Chem. 272, 32719-32722.

Huttenlocher, A., Lakonishok, M., Kinder, M., Wu, S., Truong, T., Knudsen, K. A. and Horwitz, A. F. (1998). Integrin and cadherin synergy regulates contact inhibition of migration and motile activity. J. Cell Biol. 141, 515-526.

Hynes, R. O. (1992). Integrins: versatility, modulation, and signaling in cell adhesion. Cell 69, 11-25.

Ilic, D., Furuta, Y., Kanazawa, S., Takeda, N., Sobue, K., Nakatsuji, N., Nomura, S., Fujimoto, J., Okada, M. and Yamamoto, T. (1995). Reduced cell motility and enhanced focal adhesion contact formation in cells from FAK-deficient mice. Nature 377, 539-544.

Katz, B. Z., Zamir, E., Bershadsky, A., Kam, Z., Yamada, K. M. and Geiger, B. (2000). Physical state of the extracellular matrix regulates the structure and molecular composition of cell-matrix adhesions. Mol. Biol. Cell 11, 1047-1060.

Kaverina, I., Rottner, K. and Small, J. V. (1998). Targeting, capture, and stabilization of microtubules at early focal adhesions. J. Cell Biol. 142, 181190.

Kaverina, I., Krylyshkina, O. and Small, J. V. (1999). Microtubule targeting of substrate contacts promotes their relaxation and dissociation. J. Cell Biol. 146, 1033-1044.

Kaverina, I., Krylyshkina, O., Gimona, M., Beningo, K., Wang, Y. L. and Small, J. V. (2000). Enforced polarisation and locomotion of fibroblasts lacking microtubules. Curr. Biol. 10, 739-742.

Klinghoffer, R. A., Sachsenmaier, C., Cooper, J. A. and Soriano, P. (1999).
Src family kinases are required for integrin but not PDGFR signal transduction. EMBO J. 18, 2459-2471.

Kulkarni, S., Saido, T. C., Suzuki, K. and Fox, J. E. (1999). Calpain mediates integrin-induced signaling at a point upstream of Rho family members. J. Biol. Chem. 274, 21265-21275.

Lauffenburger, D. A. and Horwitz, A. F. (1996). Cell migration: a physically integrated molecular process. Cell 84, 359-369.

Laukaitis, C. M., Webb, D. J., Donais, K. and Horwitz, A. F. (2001). Differential dynamics of alpha 5 integrin, paxillin, and alpha-actinin during formation and disassembly of adhesions in migrating cells. J. Cell Biol. 153, 1427-1440

Maki, M., Bagci, H., Hamaguchi, K., Ueda, M., Murachi, T. and Hatanaka, M. (1989). Inhibition of calpain by a synthetic oligopeptide corresponding to an exon of the human calpastatin gene. J. Biol. Chem. 264, 18866-18869.

Murachi, T., Tanaka, K., Hatanaka, M. and Murakami, T. (1980). Intracellular $\mathrm{Ca}^{2+}$-dependent protease (calpain) and its high-molecularweight endogenous inhibitor (calpastatin). Adv. Enzyme Regul. 19, 407-424.

Otey, C. A., Vasquez, G. B., Burridge, K. and Erickson, B. W. (1993). Mapping of the alpha-actinin binding site within the beta 1 integrin cytoplasmic domain. J. Biol. Chem. 268, 21193-21197.

Palecek, S. P., Huttenlocher, A., Horwitz, A. F. and Lauffenburger, D. A. (1998). Physical and biochemical regulation of integrin release during rear detachment of migrating cells. J. Cell Sci. 111, 929-940.

Pavalko, F. M. and Burridge, K. (1991). Disruption of the actin cytoskeleton after microinjection of proteolytic fragments of alpha-actinin. J. Cell Biol. 114, 481-491.

Potter, D. A., Tirnauer, J. S., Janssen, R., Croall, D. E., Hughes, C. N., Fiacco, K. A., Mier, J. W., Maki, M. and Herman, I. M. (1998). Calpain regulates actin remodeling during cell spreading [published erratum appears in J. Cell Biol. 141, 1287]. J Cell Biol. 141, 647-662.

Ruoslahti, E., Hayman, E. G., Pierschbacher, M. and Engvall, E. (1982). Fibronectin: purification, immunochemical properties, and biological activities. Methods Enzymol. 82, 803-831.

Sampath, R., Gallagher, P. J. and Pavalko, F. M. (1998). Cytoskeletal interactions with the leukocyte integrin beta2 cytoplasmic tail. Activationdependent regulation of associations with talin and alpha-actinin. J. Biol. Chem. 273, 33588-33594.

Schoenwaelder, S. M. and Burridge, K. (1999). Bidirectional signaling between the cytoskeleton and integrins. Curr. Opin. Cell Biol. 11, 274-286.

Sieg, D. J., Hauck, C. R. and Schlaepfer, D. D. (1999). Required role of focal adhesion kinase (FAK) for integrin-stimulated cell migration. J. Cell Sci. 112, 2677-2691.

Smilenov, L. B., Mikhailov, A., Pelham, R. J., Marcantonio, E. E. and Gundersen, G. G. (1999). Focal adhesion motility revealed in stationary fibroblasts. Science 286, 1172-1174.

Stewart, M. P., McDowall, A. and Hogg, N. (1998). LFA-1-mediated adhesion is regulated by cytoskeletal restraint and by a $\mathrm{Ca}^{2+}$-dependent protease, calpain. J. Cell Biol. 140, 699-707.

Trinkaus, J. P. (1984). Cells into Organs (2nd edn). Englwood Cliffs, NJ: Prentice-Hall.

Waterman-Storer, C. M. and Salmon, E. (1999). Positive feedback interactions between microtubule and actin dynamics during cell motility. Curr. Opin. Cell Biol. 11, 61-67.

Waterman-Storer, C. M., Worthylake, R. A., Liu, B. P., Burridge, K. and Salmon, E. D. (1999). Microtubule growth activates Rac1 to promote lamellipodial protrusion in fibroblasts. Nat. Cell Biol. 1, 45-50.

Zamir, E., Katz, B. Z., Aota, S., Yamada, K. M., Geiger, B. and Kam, Z. (1999). Molecular diversity of cell-matrix adhesions. J. Cell Sci. 112, 1655 1669. 